\title{
Significant Elevation of Survivin and Livin Expression in Human Colorectal Cancer: Inverse Correlation between Expression and Overall Survival
}

\author{
Ren Chong $\mathrm{Xi}^{\mathrm{a}}$ Wang Shou Biao $^{\mathrm{b}}$ Zhang Zhi Gang ${ }^{\mathrm{c}}$ \\ a'OingDao Univercity Medical College, QingDao; Cangzhou Clinical College of Integrated Traditional Chinese and Western Medicine, \\ Hebei Medicine Univercity, Cangzhou, \\ ${ }^{\mathrm{b}}$ QingDao Univercity Medical College, QingDao, \\ 'Department of Pathology, CangZhou First People's Hospital, China
}

Keywords

CRC · Survivin · Livin · Expression · Overall survival

\section{Summary}

Background: Survivin and livin are novel members of the inhibitor of apoptosis protein family, which have rarely been studied in human colorectal cancer (CRC). This study aims to examine their expression and association with clinicopathological factors and prognosis in CRC, and evaluate the possibility of their use as biomarkers for CRC. Patients and Methods: We investigated the expression of survivin and livin in 61 CRC samples using immunohistochemical staining (Envision) and correlated it with the survival of these patients using log-rank test and correlation analysis. Results: Among the 61 cases, 60.7 and $54.1 \%$ were positive for expression of survivin $(p<0.05)$ and livin $(p<0.05)$. No expression of survivin and livin was detected in normal colorectal mucosa. An inverse correlation ( $r=-0.9916)$ between the increased survivin and livin levels and overall survival was observed in univariate survival analysis. The expression of both proteins was not correlated with age, gender, degrees of differentiation, and TNM stage $(p<0.05)$ in malignancies. Conclusions: High expression of both survivin and livin may influence the prognosis of CRC. This finding opens new perspectives for CRC prognosis because survivin and livin can both be used as biomarkers or potential therapeutic targets.

\author{
Schlüsselwörter \\ CRC · Survivin · Livin · Expression · Gesamtüberleben
}

\section{Zusammenfassung}

Hintergrund: Survivin und Livin sind neue Mitglieder der IAP (inhibitor of apoptosis)-Proteinfamilie, zu denen bisher nur wenige Daten in Verbindung mit dem kolorektalen Karzinom (human colorectal cancer, CRC) existieren. Ziel der vorliegenden Studie war es, die Expression und Assoziation beider Proteine mit klinikopathologischen Faktoren und Prognose beim CRC zu untersuchen und potentielle Anwendungsmöglichkeiten als CRC-Biomarker zu bewerten. Patienten und Methoden: Wir haben die Expression von survivin und livin in 61 CRC-Proben mittels immunhistochemischer Färbung (Envision) untersucht und sie mit dem Überleben dieser Patienten mittels Log-Rank-Test und Korrelationsanalyse korreliert. Ergebnisse: Unter den 61 Fällen zeigten 60,7 bzw. 54,1\% positive Expression von Survivin $(p<0,05)$ und Livin $(p<0,05)$. In der normalen kolorektalen Mukosa wurde keine Expression von Survivin oder Livin detektiert. Die univariate Überlebensanalyse ergab eine inverse Korrelation ( $r=-0,9916)$ zwischen erhöhter Expression von survivin und livin und Gesamtüberleben. Die Expression beider Proteine war nicht mit Alter, Geschlecht, Differenzierungsgrad und TNM-Stadium $(p<0,05)$ bei Krebserkrankungen korreliert. Schlussfolgerungen: Hohe Expression von sowohl Survivin als auch von Livin könnte einen Einfluss auf die Prognose von CRC haben. Diese Erkenntnis eröffnet neue Perspektiven für die CRC-Prognose, da beide Proteine als Biomarker oder potentielle therapeutische Targets eingesetzt werden könnten.

\section{KARGER \\ Fax +497614520714 \\ Information@Karger.de}

www.karger.com (c) 2011 S. Karger GmbH, Freiburg

0378-584X/11/0348-0428\$38.00/0

Accessible online at:

www.karger.com/onk
Dr. Ren Chong Xi

Qian Tong Street no. 17, CangZhou City

HeBei Province, 061000, Chin

Tel. +8615833178533

qdrcx2008@yahoo.com.cn 


\section{Introduction}

Human colorectal cancer (CRC) is a common malignancy worldwide. It has high morbidity and mortality despite the gradual decline in its incidence in many countries [1]. Advancements in the management of CRC over the past decades have resulted in an improved prognosis. The occurrence and progression of cancer are considered to be a series of genetic events affecting the structure and/or expression of a number of oncogenes, tumor suppressors, and growth factors [2, 3]. Recent studies showed that the incidence and mortality of $\mathrm{CRC}$ are closely associated with cell apoptosis. It has been implicated in a wide variety of cell functions. Survivin and livin, which are novel members of the IAP (inhibitor of apoptosis) protein family, are upregulated in specific types of cancer. Upregulated expression of both survivin and livin has been implicated in tumorigenesis and metastasis in epithelial tumors such as CRC. Both proteins do not only promote the proliferation of tumor cells but also inhibit cell apoptosis by their upregulated expression in tumor tissues, resulting in tumorigenesis and metastasis. Most CRC have biallelic APC mutations. This is relevant to survivin overexpression because survivin is a TCF4 target gene and APC mutation leads to expansion of the population of cells expressing survivin. Survivin promotes cell proliferation, which has now been shown to be due to activation of aurora B kinase and increased mitosis [4-7]. Also, the presence of high levels of anti-livin antibodies in patients with $\mathrm{CRC}$ has been reported by 2 authors $[8,9]$. However, the underlying molecular mechanisms of these proteins remain to be elucidated.

Strong evidence for the involvement of the IAP family in the regulation of tumor progression, cellular growth, and differentiation has been found [10-12]. Previous studies have shown that survivin or livin expression is associated with tumorigenesis and metastasis in epithelial tumors including CRC. However, no study has assessed the relationship between the expression of survivin and livin and overall survival (OS). Therefore, this study aims to evaluate the role of survivin and livin in CRC and their association with clinicopathological factors, especially their relationship with OS.

\section{Patients and Methods}

\section{Patients}

A total of 61 primary CRC patients including 26 papillary adenocarcinomas, 16 tubular adenocarcinomas, 11 mucinous adenocarcinomas, and 8 signet ring cell carcinomas were studied. All tumor specimens were obtained from patients operated on at Cangzhou People's Hospital between January and December 2003. Each tumor was assigned a histological type according to the Chinese Classification of Colorectal Carcinoma, which abides by the new World Health Organization (WHO) classification of malignant tumors, and infiltration was graded according to the International Union Against Cancer TNM Classification of Malignant Tumors. The study obtained ethical approval from the local research ethics committee and observed the Helsinki Declaration. Histologically, the 61 primary human colorectal adenocarcinomas can be classified as follows: 22 tubular adenocarcinomas of the well-differentiated type, 17 tubular adenocarcinomas of the moderately differentiated type, 19 poorly differentiated adenocarcinomas of the solid type, and 3 poorly differentiated adenocarcinomas of the non-solid type. As to disease stage, 26 were in stage $1-2 b$ (TNM stage), and 35 were in stage $3 a-4 ; 21$ cases were in the recurrence and lymph node metastasis (including distant metastasis) stage. Also, 17 pericancerous tissues $(2 \mathrm{~cm}$ away from the tumor edge) were examined and studied. No cases treated by radiotherapy and/or chemotherapy were included.

A total of 32 adenomas as benign lesions with moderate dysplasia were resected by endoscopic mucosal resection (EMR). Then 17 specimens of normal colorectal mucosal tissues were evaluated as normal controls. Diagnosis was done by 2 independent pathologists, and those cases with questionable diagnosis were omitted from the study.

Of the 61 patients, 60 were involved in the follow-up study. Also, 1 case was excluded from the survival analysis (fatal car accident 13 months after surgery). All clinical data were summarized, and 60 patients were followed up 13-60 months post surgery by telephone, letter, or re-examination in the outpatient department. The last follow-up was in February 2009. Of the cases followed up, 39 were male and 22 were female, with a median age of 45 years. In total, 21 patients suffered from local recurrence (13 patients) or distant metastasis ( 8 patients) after the operation.

\section{Immunohistochemistry}

Formalin-fixed and paraffin-embedded tissues were cut into $4 \mu \mathrm{m}$ sections, deparaffinized in xylene, and rehydrated in phosphate-buffered saline. Deparaffinized sections were pre-incubated with normal rabbit serum to prevent non-specific binding, then incubated overnight at $4{ }^{\circ} \mathrm{C}$ with an optimal dilution $(0.1 \mu \mathrm{g} / \mathrm{ml})$ of a primary polyclonal rabbit antibody against human survivin (anti-survivin polyclonal rabbit antibody and anti-livin polyclonal rabbit antibody from Fuzhou New Biotechnology Ltd., Fuzhou, China and Wuhan Boster Biological Technology Ltd., Wuhan, China at working concentrations of 1:100 and 1:50, respectively). The slides were sequentially incubated with a biotinylated rabbit antirabbit immunoglobulin antibody, and the reaction products were viewed using diaminobenzidine and hematoxylin staining as counter staining. Analysis of the immunohistochemical staining was performed independently by 2 investigators. Survivin and livin expression levels were classified into 2 categories depending on the percentage of cells stained. The mean percentage of positive tumor cells for the expression of survivin and livin was determined in at least 5 areas at 400-fold magnification, and cases with less than $10 \%$ positively stained tumor cell were defined as negative, the rest as positive. This scoring was performed in a blinded fashion.

\section{Statistical Analysis}

All data were analyzed by SPSS 11.0 statistical software (SPSS Inc., Chicago, IL, USA). Analyses comparing the expression of survivin and livin were performed using the chi-square test. Survival durations were calculated using the Kaplan-Meier method. Log-rank test was used to calculate the significance of differences in the survival analysis. A probability level of $<0.05$ was considered significant. Correlation analysis was used to correlate expression of survivin and livin and OS (correlation coefficient, $\mathrm{r}-1$ and +1 ).

\section{Results}

\section{Expression and Immunohistochemical Analysis of Clinicopathological Factors}

A summary of the results for the immunohistochemical analysis is shown in table 1 . CRC tissues showed relatively high 
Table 1. Expression of survivin and livin, and clinicopathological factors

\begin{tabular}{|c|c|c|c|c|c|c|c|}
\hline \multirow[t]{2}{*}{ Factors } & \multirow{2}{*}{$\begin{array}{l}\text { Cases, } \mathrm{n} \\
(\%)\end{array}$} & \multicolumn{3}{|l|}{ Livin } & \multicolumn{3}{|l|}{ Survivin } \\
\hline & & $\mathrm{n}(\%)$ & $\mathrm{x}^{2}$ & $\mathrm{p}$ & $\mathrm{n}(\%)$ & $\mathrm{x}^{2}$ & $\mathrm{p}$ \\
\hline \multicolumn{8}{|l|}{ Age, years } \\
\hline$\geq 50$ & 40 & $22(55.0)$ & \multirow[t]{2}{*}{0.038} & \multirow{2}{*}{$>0.05$} & $24(60.0)$ & \multirow[t]{2}{*}{0.021} & \multirow[t]{2}{*}{$>0.05$} \\
\hline$<50$ & 21 & $11(52.4)$ & & & $13(61.9)$ & & \\
\hline \multicolumn{8}{|l|}{ Sex } \\
\hline Male & 39 & $21(53.8)$ & \multirow[t]{2}{*}{0.003} & \multirow{2}{*}{$>0.05$} & $23(60.1)$ & \multirow{2}{*}{0.128} & \multirow{2}{*}{$>0.05$} \\
\hline Female & 22 & $12(54.5)$ & & & $14(63.7)$ & & \\
\hline \multicolumn{8}{|l|}{ Tissue type } \\
\hline Carcinoma & 61 & $33(54.1)$ & \multirow{4}{*}{5.717} & \multirow{4}{*}{$<0.05$} & 37 (60.7) & \multirow{4}{*}{5.804} & \multirow{4}{*}{$<0.05$} \\
\hline Adenoma & 32 & $9(39.1)$ & & & $11(34.4)$ & & \\
\hline Pericancerous tissue & 17 & $2(11.8)$ & & & $3(17.6)$ & & \\
\hline Normal mucosa & 17 & $0(0.0)$ & & & $0(0.0)$ & & \\
\hline \multicolumn{8}{|l|}{ Degree of differentiation } \\
\hline Well or moderate & 39 & $22(56.4)$ & \multirow[t]{2}{*}{0.817} & \multirow{2}{*}{$>0.05$} & $24(61.5)$ & \multirow[t]{2}{*}{0.035} & \multirow[t]{2}{*}{$>0.05$} \\
\hline Poor & 22 & $11(50.0)$ & & & $13(59.1)$ & & \\
\hline \multicolumn{8}{|l|}{ TNM stage } \\
\hline $1-2 b$ & 26 & $14(53.8)$ & \multirow[t]{2}{*}{0.001} & \multirow[t]{2}{*}{$>0.05$} & $16(61.5)$ & \multirow[t]{2}{*}{0.015} & \multirow[t]{2}{*}{$>0.05$} \\
\hline $3 a-4$ & 35 & $19(59.3)$ & & & $21(60.0)$ & & \\
\hline \multicolumn{8}{|c|}{ Metastasis and/or recurrence } \\
\hline Yes & 21 & $19(90.5)$ & \multirow[t]{3}{*}{14.906} & \multirow[t]{3}{*}{$<0.01$} & $12(57.1)$ & \multirow[t]{3}{*}{0.164} & \multirow[t]{2}{*}{$>0.05$} \\
\hline No & 40 & $14(35.0)$ & & & $25(62.5)$ & & \\
\hline Overall survival & $43(70.5)$ & $20(63.6)$ & & & $24(64.2)$ & & $<0.05$ \\
\hline
\end{tabular}

Table 2. Overall survival (OS) and expression of survivin and livin

\begin{tabular}{lllll}
\hline & \multicolumn{2}{l}{ Gene expression, $\mathrm{n}$} & OS, \% & r value \\
\cline { 2 - 3 } & present & absent & & \\
\hline Survivin & 21 & 3 & 87.5 & -0.8836 \\
$\quad$ Negative & 24 & 13 & 64.9 & \\
$\quad$ Positive & & 2 & 92.9 & -0.9895 \\
Livin & 26 & 15 & 54.5 & \\
$\quad$ Negative & 18 & & & \\
$\quad$ Positive & & 46 & 24.6 & -0.9916 \\
$\quad$ Survivin + livin & 15 & & & \\
$\quad$ Positive & & & & \\
\hline
\end{tabular}

expression of survivin and livin. Among 61 cases of adenocarcinoma, 37 cases $(60.7 \%)$ and 33 cases $(54.1 \%)$ showed positive staining for survivin and livin in the cytoplasm of carcinoma cells $(\mathrm{p}<0.05)$, respectively. On the other hand, only 34.4 and $39.1 \%$ of adenoma cases with moderate dysplasia resected by EMR had positive staining for survivin and livin ( $\mathrm{p}>0.05)$, respectively. Furthermore, survivin and livin $(17.6,11.8 \%)$ were also expressed in pericancerous tissue cells $(\mathrm{p}>0.05)$. No expression of survivin and livin was detected in normal colorectal mucosa (table 1). The expression of survivin and livin was not correlated with age, gender, TNM stage, and degree of histological differentiation. Livin expression was significantly correlated with the recurrence and presence of lymph node metastasis $(\mathrm{p}<0.01)$ in total carcinoma.

\section{Overall Survival Analysis and Prognosis after Surgery}

The OS in 61 patients with CRC was analyzed based on the expression of survivin and/or livin (table 2). Using the Kaplan-Meier and correlation analysis method, the expression of survivin and livin was found to be inversely associated with OS $(r=-0.9916)$, and the correlation coefficients of both were -0.8836 and -0.9895 , respectively. With negative expression for survivin and livin, OS was 87.5 and $92.9 \%$, respectively. All present CRC cases were negative for survivin and livin, whereas the remaining 5 patients $(12.5$ and $7.1 \%)$ died from primary carcinoma: 3 were negative for survivin, and 2 were negative for livin (fig. 1).

\section{Discussion}

CRC remains a common disease worldwide, but it has a poor prognosis and low survival rates. This can be attributed to the poor understanding of the $\mathrm{CRC}$ molecular controls. The involvement of a number of different cell death or proliferation-modifying genes has been proposed. Specifically, the expression of the apoptosis inhibitors survivin and livin is characteristic of CRC and other malignancies. These proteins are specific as they are not expressed in most mature tissues (except for placenta etc.), and they are expressed highly in embryonic tissue and the majority of solid tumor tissues [13, 14]. In addition to their anti-apoptosis effect, survivin and livin affect diverse functions in the regulation of critical biological functions such as cell cycle regulation, metabolism, cellular differentiation and transformation, cell adhesion, and promotion of neovascularization [14-17]. Several studies have shown that survivin is not expressed in normal adult tissues but in almost all malignant tumors to varying degrees (positive rate of $30-100 \%$ ) [18]. However, recently published studies show that survivin is in fact expressed in normal colonic epithelium $[4,6,7]$. The dual functions of cell apoptosis and proliferation contribute to the regulation of survivin [19]. Livin is overexpressed in a variety of gastrointestinal 

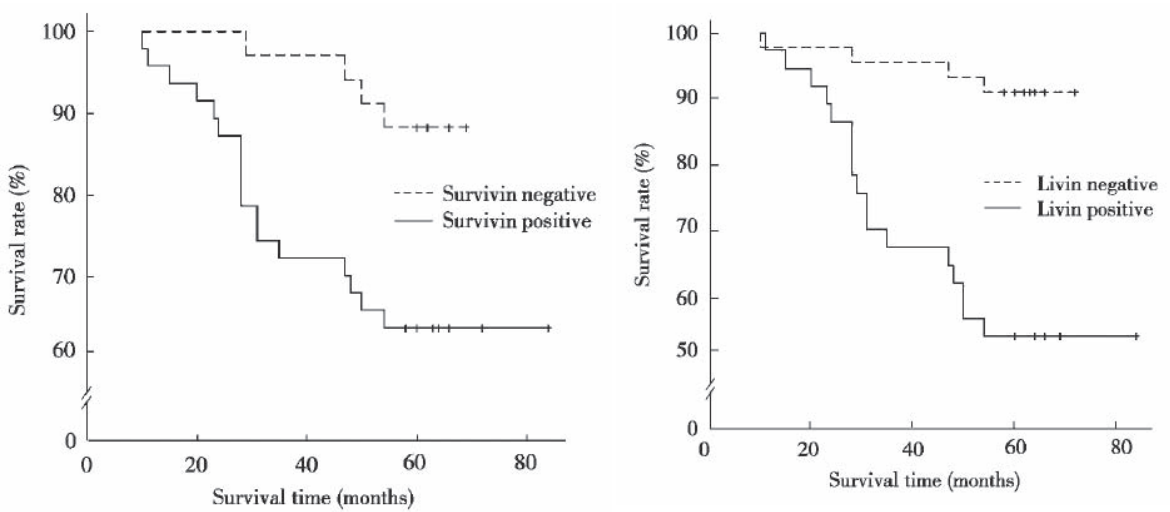

Fig. 1. Overall survival (OS): time-survival curve (Kaplan-Meier); OS based on expression of survivin and/or livin in CRC $(\mathrm{n}=61)$; expression inversely associated with OS in univariate survival analysis. tumors such as gastric cancer, CRC, pancreatic cancer, and hepatoma [20-22], and it is correlated with the degree of malignancy and prognosis. In cancer research, tumor progression, local invasion, and tumor metastases determine the prognosis of cancer patients. Although the cellular mechanisms of metastasis affect different tumor cell properties [23, 24], an important initial step in cancer metastasis is invasion into the capillary and/or lymph ducts through tight endothelial junctions. Some factors, such as growth factors and cytokines derived from cancer cells, alter vascular permeability $[25,26]$.

The results of the present study provide greater support for an oncogenic (proliferative) role of livin and survivin in $\mathrm{CRC}$, which concurs with the findings of Langlois et al. [27] on survivin and livin expression in association with cell proliferation and growth factor. Many studies indicated that survivin and livin play an important role in tumorigenesis, especially in colorectal tumorigenesis. It is possible that some cancer prevention agents may function by inhibiting the expression of both. Expression of survivin in cancer cells is strongly associated with drug and radiation resistance, and many chemoprevention agents may exert their cancer prevention effects by inhibiting the expression of survivin. Growing evidence has revealed an essential role for survivin in cancer cell resistance to chemotherapy and radiation therapy. As with survivin overexpression, livin overexpression by cancer cells may lead to anti-livin antibody responses and cytotoxic T-lymphocyte responses against the cancer. As such, livin inhibits apoptosis, and its overexpression renders malignant cells resistant to chemotherapy. Several studies have demonstrated that downregulation of livin expression increases the apoptotic rate, reduces tumor growth potential, and sensitized tumor cells to chemotherapeutic drugs. Therefore, inhibitors of survivin and livin could be useful adjuncts to chemotherapy in the treatment of malignancies.

We speculated that survivin or livin play important roles in the development and progression of CRC. This hypothesis was primarily based on consistent epidemiological evidence and strong biological support for the critical roles of survivin or livin (as anti-apoptosis factors) in the regulation of cell growth and differentiation. This is the first study to investigate the roles of survivin and livin in CRC. In this research, the expression of survivin and livin was examined in CRC using immunohistochemical and molecular biological techniques. The results showed that the 2 proteins were expressed in $\mathrm{CRC}$ and were correlated with several clinicopathological factors, especially recurrence and metastasis. However, their expression was not correlated with age, gender, TNM stage, and degree of histological differentiation. The livin expression rate in lymph node metastasis and/or recurrence was higher than the survivin expression rate, and the difference was statistically significant. Further, statistical analysis of the data indicated a correlation between survivin and livin expression and the recurrence of tumor, lymph duct invasion, and metastasis to the lymph nodes (table 1). An inverse correlation between gene expression and OS was found. Tumor metastasis is a common feature in several malignant human tumors, and a poorly defined tumor border at the invasive tumor edge is associated with a poor prognosis in CRC [28]. However, a relationship between OS and expression of survivin and livin in CRC has not been reported. In this study, their expression in carcinoma cells was significantly inversely correlated with OS. These results suggest that the expression of both proteins could potentially be another prognostic factor in CRC consistent with the findings of $\mathrm{He}$ et al. [29]. On the other hand, Kasof and Gomes [30] reported that livin in the metastatic lymph nodes shows faint expression, and that there is no association between the expression of livin in carcinoma cells and metastasis to the lymph nodes or OS. The study by Sarela et al. [31] showed that the 5-year survival rate of survivin-positive patients with CRC was significantly lower than that of survivin-negative patients. Kawasaki et al. [32] and Song et al. [33] had similar findings. No expression of survivin and livin in normal colorectal mucosa was inconsistent results with them $[4,6,7]$. In the present study, OS in patients with positive expression of survivin and livin was found to be inversely correlated.

The survival rate was significantly better in patients without expression of survivin and livin. A total of 61 cases were investigated, and many cases with short-term follow-up were 
involved. Further investigation into the detailed prognostic evaluation using a larger sample is warranted. In this study, the cause of death in 18 of the follow-up cases was distant metastasis to other organs (tables 1 and 2). Further, all 18 cases with distant metastases were positive for livin. All present cases with CRC were negative for survivin and livin, whereas the remaining 5 patients $(12.5 \%$ and $7.1 \%)$ died from the disease. Patients with expression of survivin and livin have the worst survival outcome due to the high incidence of distant metastasis. A statistical difference in the OS of patients with or without expression was found. These findings suggest that survivin and livin are involved in the prognosis of CRC. However, their role has not been fully clarified in cancer biology, particularly the relationship between the expression of both proteins and the clinicopathological features of CRC. Therefore, the detailed mechanisms involving survivin and livin in CRC require further investigation.

\section{Conflict of Interest Statement}

The authors declare that they have no competing interests.

\section{References}

1 Casciato DA, Lowitz BB (eds): Manual of Clinical Oncology, 4th ed. Philadelphia, PA, Lippincott Williams \& Wilkins Inc., 2001, p. 182

2 Vogelstein B, Fearon ER, Hamilton SR, Kern SE, Preisinger AC, Leppert M, Nakamura Y, White R, Smits AM, Bos JL: Genetic alterations during colorectal tumor development. New Engl J Med 1988:319:525-532.

3 Ming SC, Goldman H (eds): Pathology of the Gastrointestinal Tract, 2nd ed. Baltimore, MD Williams \& Wilkins, 1998, pp. 632-633.

4 Zhang T, Otevrel T, Gao Z, et al.: Evidence that APC regulates survivin expression: a possible mechanism contributing to the stem cell origin of colon cancer. Cancer Res 2001;61:8664-8667.

$\checkmark 5$ Kim PJ, Plescia J, Clevers H, et al.: Survivin and molecular pathogenesis of colorectal cancer. Lancet 2003;362:205-209.

6 Boman BM, Walters R, Fields JZ, et al.: Colonic crypt changes during adenoma development in familial adenomatous polyposis: immunohistochemical evidence for expansion of the crypt base cell population. Am J Pathol 2004;165:1489-1498.

7 Zhang T, Fields JZ, Opdenaker L, et al.: Survivininduced Aurora-B kinase activation: a mechanism by which APC mutations contribute to increased mitoses during colon cancer development. Am J Pathol 2010;177:2816-2826.

8 Yagihashi A, Asanuma K, Tsuji N, et al.: Detection of anti-livin antibody in gastrointestinal cancer patients. Clin Chem 2003;49:1206-1208.

$\checkmark$ El Ali Z, Grzymislawski M, Majewski P, et al. Anti-livin antibodies: novel markers of malignant gastrointestinal cancers. Pol Arch Med Wewn 2010;120:26-29.

10 Nakayama T, Hatachi G, Wen CY, Oshizaki A, Yamazumi K, Niino D, Sekine I: Expression and significance of Tie-1 and Tie-2 receptors, and angiopoietins-1, 2 and 4 in colorectal adenocarcinoma: immunohistochemical analysis and correlation with clinicopathological factors. World J Gastroenterol 2005;11:964-969.
11 Bach F, Uddin FJ, Burke D: Angiopoietins in malignancy. Eur J Surg Oncol 2007;33:7-15.

12 Nakayama T, Yoshizaki A, Kawahara N, Ohtsuru A, Wen CY, Fukuda E, Nakashima M, Sekine I: Expression of Tie- 1 and 2 receptors, and angiopoietin-1, 2 and 4 in gastric carcinoma; immunohistochemical analyses and correlation with clinicopathological factors. Histopathology 2004;44:232-239.

13 Lin JH, Deng G, Huang Q, Morser J: KIAP, a novel member of the inhibitor of apoptosis protein family. Biochem Biophys Res Commun 2000;279:820-831.

14 Nesbit CE, Tersak JM, Prochownik EV: MYC oncogenes and human neoplastic disease. Oncogene 1999;18:3004-3016.

15 Henriksson M, Luscher B: Proteins of the Myc network: essential regulators of cell growth and differentiation. Adv Cancer Res 1996;68:109-182.

16 Oster SK, Ho CS, Soucie EL, et al.: The myc oncogene: MarvelouslY Complex. Adv Cancer Res 2002;84:81-154.

17 Evan GI, Wyllie AH, Gilbert CS, et al.: Induction of apoptosis in fibroblasts by c-myc protein. Cell 1992;69:119-128.

18 Koch CA, Vortmey AO, Diallo R, et al.: Survivin: a novel neuroendocrine marker for pheochromocytoma. Eur J Endorinol 2002;1:381-388.

19 Watson AJ: An overview of apoptosis and the prevention of colorectal cancer. Crit Rev Oncol Hematol 2006;57:107-121.

20 Vucic D, Stennicke HR, Pisabarro MT, et al.: MLIAP, a novel inhibitor of apoptosis that is preferentially expressed in human melanomas. Curr Biol 2000;10:1359-1366.

21 Takahashi R, Deveraux Q, Tamm L, et al.: A single BIR domain of XIAP sufficient for inhibiting caspases. J Biol Chem 1998;273:7787-7790.

22 Yagihashi A, Asanuma K, Tsuji N, et al.: Detection of anti livin antibody in gastrointestinal cancer patients. Clin Chem 2003;49:1206-1208.
23 Crissman JD, Hatfield JS, Menter DG, Sloane B, Honn KV: Morphological study of the interaction of intravascular tumor cells with endothelial cells and subendothelial matrix. Cancer Res 1988;48: 4065-4072.

24 Hynes RO: Integrins: bidirectional, allosteric signaling machines. Cell 2002;110:673-687.

25 Carmeliet P: Angiogenesis in health and disease. Nat Med 2003;9:653-660.

26 Achen MG, McColl BK, Stacker SA: Focus on lymph angiogenesis in tumor metastasis. Cancer Cell 2005;7:121-127.

27 Langlois NE, Lamb J, Eremin O, et al.: Apoptosis in colorectal carcinoma occurring in patients aged 45 years and under: relationship to prognosis, mitosis, and immunohistochemical demonstration of p53, c-myc and bcl-2 protein products. J Pathol 1997;182:392-397.

28 Halvorsen TB, Seim E: Association between invasiveness, inflammatory reaction, desmoplasia and survival in colorectal cancer. J Clin Pathol 1989;42:162-166.

29 He JT, Li ZF, Zhang YD, et al.: The expression significance of apoptosis inhibitor Livin in colorectal cancer. Chin J Mod Med 2007,17:654657.

30 Kasof GM, Gomes BC: Livin, a novel inhibitor of apoptosis protein family member. J Biol Chem 2001;276:3238-3246.

31 Sarela AI, Macadam RC, Farmery SM, et al.: Expression of the antiapoptosis gene, survivin, predicts death from recurrent colorectal carcinoma. Gut 2000;46:645-650.

32 Kawasaki H, Toyoda M, Shiohara H, et al.: Expression of survivin correlated with apoptosis, proliferation, and angiogences is during human colorectal tumorigenesis. Cancer 2001;91:20262032.

33 Song YC, Wan DS, Pan ZZ: Survivin expression of Dukes' $\mathrm{C}$ in colorectal cancer and its biological significance. Chin J Clin Oncol 2005;32:979-983. 